Short Communication

\title{
Potential impact of Nootka lupine (Lupinus nootkatensis) invasion on pollinator communities in Iceland
}

\author{
Jonathan Willow ${ }^{1}$, Mariana Tamayo ${ }^{1}$ and Magnús H. Jóhannsson ${ }^{2}$ \\ ${ }^{I}$ Environment and Natural Resources, University of Iceland, Sturlugata 7, 101 Reykjavik, Iceland. \\ e-mail: jonathan.willow@student.emu.ee (correspondingauthor),mlt@hi.is \\ ${ }^{2}$ Soil Conservation Service of Iceland, Gunnarsholt, 851 Hella, Iceland.e-mail: magnus@land.is
}

Keywords: invasive species, insect, Bombus, Diptera, subarctic, pollination

\section{INTRODUCTION}

Pollinator communities have an integral role in facilitating sexual reproduction within and between flowering plant populations. Declines in abundance and diversity of pollinating insects are widely documented throughout Europe, primarily the result of habitat loss and fragmentation (Fox 2013, Nieto et al. 2014, Goulson et al. 2015).

In 1945, seeds of Nootka lupine (Lupinus nootkatensis Donn) were collected in Alaska, brought to Iceland, and introduced at reforestation sites. This plant's invasiveness in Iceland was indicated by its tendency to replace native vegetation with homogeneous $L$. nootkatensis stands (Magnússon 2010).

The lack of published research on Iceland's broader pollinator community, combined with the dramatic changes in vegetation that have taken place over the last few decades, particularly with L. nootkatensis's distribution, warrants an analysis of plant-pollinator relationships in Iceland, especially regarding $L$. nootkatensis. The present study aims to describe how pollinator communities differ between $L$. nootkatensis and the native flowering plants in heath habitat in south-west Iceland. The findings of this study will give an indication of whether L. nootkatensis can serve as an alternative food source for Iceland's pollinator community, in the event that L. nootkatensis continues to replace native flowering plant communities throughout Iceland.

\section{MATERIALS AND METHODS}

Sampling was conducted within a $0.58 \mathrm{~km}^{2}$ area of heath habitat adjacent to Lake Vífilsstaðavatn, in Heiðmörk, a nature reserve in south-west Iceland. Here, the flowering plant network was represented by a mosaic of native woody and herbaceous flowering plant patches and dense L. nootkatensis stands, with $L$. nootkatensis dominating much of the landscape surrounding the site.

Insects were collected from 21 June to 3 August 2015, during the flowering period of L. nootkatensis. Sampling took place under full sun and in low-wind conditions, in order to reflect maximum pollinator activity, and surveys consisted of timed meanderings within sampled patches. The timed meander method was considered ideal, as it was likely to detect a higher number and diversity of pollinators, and provide a more accurate snapshot of the pollinator community, due to the greater amount of area sampled. Moreover, as the flowering plant composition of the study area was a mosaic of L. nootkatensis patches and patches of native flowering plants, the size and shape of the 
patches sampled varied greatly, making transectwalking difficult to standardize, replicate, and accurately capture the variability of the plant community mosaic. Each timed meander was 30 minutes, and each 30-minute survey focused on a patch of either L. nootkatensis or native flowering plants. On each day of sampling, equal time was spent collecting insects in both of these plant community categories, and the plant community in which sampling took place changed after each 30-minute sampling segment. Sampling took place on 9 different days, with a total of 64 surveys being conducted (32 for both L. nootkatensis and native plants). A standard slow walking pace was used for all surveys, making the total area surveyed comparable for both $L$. nootkatensis and native flowering plants.

If an insect was in contact with a reproductive structure of a flower, it was considered a potential pollinator, and subsequently euthanized in a jar containing a cotton ball moistened with $100 \%$ acetone. Insects were preserved in $80 \%$ ethanol and later identified to their taxonomic family, except for bees which were identified to species. Comparisons of pollinator richness and abundance were made between $L$. nootkatensis and native flowering plants.

\section{RESULTS}

A total of 767 flower-visiting insects from 24 families were collected, including insects of the orders Diptera, Hymenoptera, Trichoptera, Lepidoptera, and Coleoptera. The majority, 647 individuals (84\%, 22 families), occurred on native plants. In contrast, only 120 individuals (16\%, 12 families) were found on L. nootkatensis. The most frequently observed flower visitors were bees from the family Apidae, followed by flies from the families Bibionidae, Fanniidae, Muscidae, Chironomidae, and Syrphidae (Fig. 1a).

On native plants, the most common insects were from the families Apidae, Bibionidae, Fanniidae, Muscidae, Syrphidae, and Chironomidae (Fig. 1a). In contrast, the most common insects on L. nootkatensis were from Apidae, Chironomidae, Muscidae, Lauxaniidae,
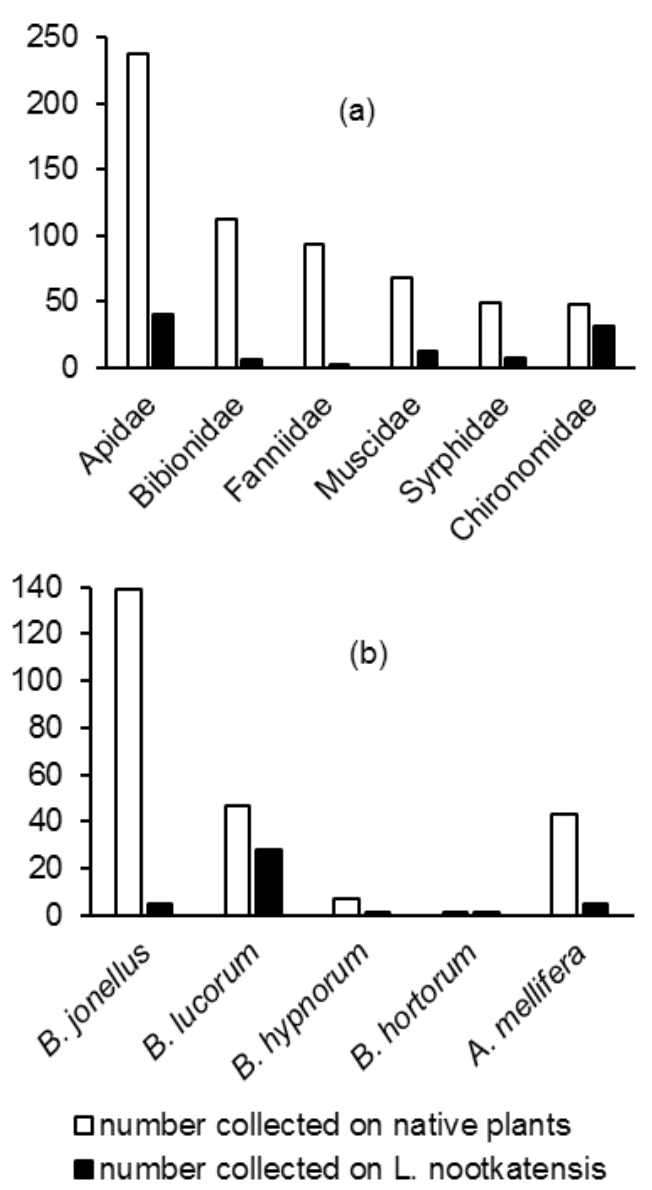

Figure 1. (a) Number of insects collected on Lupinus nootkatensis and native flowering plants, for the six most common insect families encountered; and (b) number of bees collected on L. nootkatensis and native flowering plants, for each bee species encountered $($ A. $=$ Apis, $B$. $=$ Bombus $)$.

Syrphidae, and Bibionidae. Interestingly, flies of the families Lauxaniidae and Acartophthalmidae were only observed on L. nootkatensis. However, flies of the families Simuliidae, Sciaridae, Ditomyiidae, Phoridae, Lonchopteridae, Dolichopodidae, and Empididae were only found on native plants. Similarly, insects from the parasitoid wasp families Pteromalidae, Braconidae, and Eulophidae, as well as the wasp families Tenthredinidae and Vespidae, were only detected on native plants. The remaining 
families Limnephilidae (Trichoptera), Geometridae (Lepidoptera), Chrysomelidae (Coleoptera), and Tipulidae (Diptera) occurred on both $L$. nootkatensis and native flowering plants.

Five bee species from the family Apidae were detected in our study, and all five were collected on both $L$. nootkatensis and native plants (Fig. 1b). Four of these species were bumblebees (Bombus jonellus Kirby, B. lucorum L., B. hypnorum L., and B. hortorum L.), while the fifth was the European honeybee (Apis mellifera L.). There were 139 B. jonellus visits on native plants, and only 5 on $L$. nootkatensis. $B$. lucorum, B. hypnorum, and A. mellifera were also more frequent on native plants, while $B$. hortorum was found foraging equally on both $L$. nootkatensis and native plants.

Samples were inadvertently pooled in the laboratory, so we know only the total number of individuals collected for each taxon. Focusing on the six most common insect families $(92 \%$ of total insects collected, Fig. 1a), we saw a statistically significant difference $(\mathrm{t}=2.85$; $\mathrm{df}=10 ; \mathrm{p}=0.017$ ) between the number of insects collected from native plants compared to $L$. nootkatensis, with significantly more insects found on native plants. While $86 \%$ of all bee observations, and $97 \%$ of $B$. jonellus observations, occurred on native plants, analysis of our data did not confirm a statistically significant difference between the number of bees found on native plants and L. nootkatensis $(\mathrm{p}=0.078)$, likely due to a shortage of data.

\section{DISCUSSION}

Our study revealed clear differences between the communities of potential pollinators visiting the invasive plant $L$. nootkatensis and native flowering plants in heath habitat in southwest Iceland. The relative lack of visits to $L$. nootkatensis raises concern over its suitability as an alternative food source for the majority of flower-visiting insects in Iceland. Its floral displays are larger and showier than those of any native species at the study site. However, $L$. nootkatensis flowers require a degree of pressure to be applied (e.g. a bumblebee landing) on the lower "wing" petals in order for the flower's "keel", which holds the stamens, to be exposed. This feature may account in part for the relative lack of visits by certain insect taxa, as foraging upon L. nootkatensis may often be limited to circumstances where the keel has already been exposed by a visiting bumblebee.

We saw dramatically more visits by $B$. jonellus to native flowering plants than to $L$. nootkatensis. B. jonellus is the only native bee species in Iceland, and therefore a conservation priority. With that in mind, in combination with L. nootkatensis's expanding distribution, the fact that $97 \%$ of $B$. jonellus foraging observations occurred on native flowering plants is of great concern. Our data suggest that L. nootkatensis may have negligible value as a forage plant for B. jonellus. Moreover, recent findings give us reason to suspect that the consumption of L. nootkatensis pollen may negatively impact reproduction in bumblebee populations that forage more frequently on $L$. nootkatensis (e.g. B. lucorum). Arnold et al. (2014) studied the effects of the toxic compound $D$-lupanine on B. terrestris L., using levels equivalent to those detected in the pollen of lupines. Colonies receiving pollen with $D$-lupanine produced fewer males than colonies that did not receive $D$-lupanine, and the size of males (an indicator of colony fitness) was negatively correlated with $D$-lupanine concentration.

The importance of hover flies (Syrphidae) as pollinators is widely-acknowledged (Larson et al. 2001), and $88 \%$ of hover flies in our study were collected on native plants (Fig. 1a). Non-syrphid flies are also important pollinators. Recent research analysing pollen loads in temperate ecosystems estimated that $84 \%$ of pollen carried by flies was carried by non-syrphid flies (Orford et al. 2015). In high latitudes, the role of flies as pollinators is likely further increased due to their high numbers (Kevan 1972, Lindegaard \& Jónasson 1979). Non-syrphid flies were common pollinators in our study, representing $50 \%$ of insects collected, and $87 \%$ of flies collected. Flies of the families Bibionidae, Fanniidae, and Muscidae were notably more abundant on native plants compared to L. nootkatensis (Fig. 
1a), suggesting a mutual dependency between Iceland's native flowering plant community and these important dipteran taxa.

About $10 \%$ of insects collected in our study were non-biting midges (Chironomidae), and $60 \%$ of these were collected on native plants. Although the role of midges as pollinators in northern ecosystems is not well understood, their abundance in northern ecosystems such as Iceland's Lake Mývatn (Lindegaard \& Jónasson 1979) suggests the need to further investigate their effectiveness as pollinators in these ecosystems.

We suggest that $L$. nootkatensis is inadequate as an alternative food source for the majority of Iceland's pollinator community. If $L$. nootkatensis continues to replace native flowering plant communities throughout Iceland, mutualistic insect partners of native plant communities could undergo population declines. This represents a positive-feedback cycle potentially resulting in an ecological shift, from a state where plant-pollinator mutualisms sustain themselves, to a state where numerous plant-pollinator mutualisms are lost. Long-term data on plant-pollinator interactions and changes in flowering plant communities, both native and invasive, would greatly enhance our ability to predict and prevent undesirable changes in Iceland's plant-pollinator network.

\section{ACKNOWLEDGEMENTS}

We thank Ólafur Patrick Ólafsson for providing laboratory space. We also thank Victor Pajuelo Madrigal, Kristján Kristjánsson, and Eve Veromann for their valuable input.

\section{REFERENCES}

\section{Arnold SEJ, Idrovo MEP, Arias LJL, Belmain}

SR, Stevenson PC 2014. Herbivore defense compounds occur in pollen and reduce bumblebee colony fitness. Journal of Chemical Ecology 40, 878-881.

https://doi.org/10.1007/s10886-014-0467-4

Fox R 2013. The decline of moths in Great Britain: a review of possible causes. Insect Conservation and Diversity 6, 5-19.

https://doi.org/10.1111/j.1752-4598.2012.00186.x
Goulson D, Nicholls E, Botías C \& Rotheray EL 2015. Bee declines driven by combined stress from parasites, pesticides, and lack of flowers. Science 347, 1435-1444.

Kevan PG 1972. Insect pollination of high arctic flowers. Ecology 60, 831-847.

https://doi.org/10.2307/2258569

Larson BMH, Kevan PG \& Inouye DW 2001. Flies and flowers: taxonomic diversity of anthophiles and pollinators. The Canadian Entomologist 133, 439-465.

https://doi.org/10.4039/ent133439-4

Lindegaard C \& Jónasson PM 1979. Abundance, population dynamics and production of zoobenthos in Lake Mývatn, Iceland. Oikos 32, 202-227.

https://doi.org/10.2307/3544228

Magnússon B 2010. NOBANIS - Invasive Alien Species Fact Sheet - Lupinus nootkatensis. In: Online Database of the European Network on Invasive Alien Species - NOBANIS. Accessed 20.04.2016 at https://www.nobanis.org/ globalassets/speciesinfo///lupinus-nootkatensis/ lupinus_nootkatensis.pdf.

Nieto A and 26 others 2014. European Red List of bees. Publication Office of the European Union, Luxembourg, $84 \mathrm{p}$.

Orford KA, Vaughan IP \& Memmott J 2015. The forgotten flies: the importance of non-syrphid Diptera as pollinators. Proceedings of the Royal Society B, 282.

https://doi.org/10.1098/rspb.2014.2934

Manuscript received 20 June 2017 Accepted 30 August 2017 